\title{
Corrosion of metals in zinc nitrate hexahydrate and calcium chloride hexahydrate
}

\author{
Kristína Oravcová, Vladimír Danielik \\ Institute of Inorganic Chemistry, Technology and Materials, \\ Faculty of Chemical and Food Technology STU in Bratislava, \\ Radlinského 9, 81237 Bratislava, Slovak Republic \\ oravcova.kristina@gmail.com
}

\begin{abstract}
Materials used for heat accumulation are substances with the phase change at temperatures below $80^{\circ} \mathrm{C}$. In such substances, a high amount of energy can be stored due the phase change. Because of possible corrosion of the heat container components, it is necessary to know their resistance in the given medium. In this work, the corrosion of aluminum, copper and carbon steel was studied in two liquid media: zinc nitrate hexahydrate and calcium chloride hexahydrate. Corrosion tests have shown that steel is the least resistant to corrosion in both media. Aluminum has been proved as the most durable material in zinc nitrate hexahydrate media. On the other hand, pitting corrosion on aluminum occurred in the calcium chloride hexahydrate making it unsuitable for the use in this media. From the comparison of two studied PCMs follows that zinc nitrate hexahydrate is a more aggressive medium in comparison with calcium chloride hexahydrate. From the point of view of corrosion, zinc nitrate hexahydrate is not suitable for heat accumulation when using the studied metals. When using the calcium chloride hexahydrate as PCM, copper is suitable as a construction material; aluminum and carbon steel show pitting corrosion.
\end{abstract}

Key words: heat accumulation, corrosion, carbon steel, aluminum, copper, PCM

\section{Introduction}

Nowadays, carbon dioxide is responsible for more than $50 \%$ of the greenhouse effect, which is the main cause of the climate change. It is mainly produced by combustion of fossil fuels. Therefore, more importance is attached to the use of renewable energy sources. In recent years, solar systems have become more popular and more common. Solar power plants produce electricity in the same way as conventional power plants but using solar radiation as feedstock. On the other hand, solar collectors using sun irradiation for heat production are common for "home use". When using solar energy as the primary source of energy production, it is necessary to store the produced heat; therefore, systems for heat energy accumulation are being developed to save the heat for later application. Currently, sensible heat storage containers are more commonly used, utilizing sensible heating of materials with lower specific heat capacity and limited capacity to store bigger amounts of energy. The use of latent heat as a source of energy is desirable in these systems. In latent heat storage, the materials store heat while changing phase (Sharma et al., 2005). Because of the low melting temperature and the ability to efficiently accumulate large amounts of heat, various phase change materials (PCMs) are tested. PCMs are substances that are able to accumulate large amounts of heat during the phase change. The phase change solid-to-liquid is the most used, but also solid-to-solid change is interesting. The main characteristic of this technology is the constant temperature of the material during the phase change (Farid et al., 2004). Real systems show temperature stabilization around the melting temperature. PCMs are mostly chosen based on cost, which reflects their availability. When selecting the PCM material, technical requirements for a suitable design have to be taken into account. To achieve the longest construction material life, it has to meet certain criteria: minimum phase change volume the storage material should be chemical stability, and non-toxicity in the environment. Storage media have to be compatible with the construction material; it is therefore necessary to verify its corrosion properties, which are important for long-term durability in cyclic processes particularly at elevated temperatures (Gil et al., 2010).

Corrosion of metallic materials in inorganic hydrates is of increasing interest. However, PCMs introduced in this paper were studied only in a few papers (Cabeza et al., 2001a; Cabeza et al., 2001b). Cabeza et al. (2001a) tested the corrosive properties of zinc nitrate hexahydrate upon short-term 14 days contact with metals (stainless steel, brass, steel, aluminum, copper). They observed that zinc nitrate hexahydrate is extremely corrosive to brass (Ms58 Flach), steel (1.0345), aluminum (EN AW 2007) and copper (E-Cu 57). The only material resistant to corrosion in zinc nitrate hexahydrate is stainless steel (1.4301). The same results were presented by Cabeza et al. (2001b) upon a 75 day contact of the metals with the 
medium. Corrosion resistance of metallic materials in calcium chloride hexahydrate has not been published in open literature until now.

In this paper, zinc nitrate hexahydrate and calcium chloride hexahydrate were tested as PCMs. This work focuses on the study of corrosion of aluminum (EN AW 1050A), copper (EN CW004A) and carbon steel, which are the usual components of heat storage. Corrosion process was monitored in both PCMs.

\section{Experimental}

Aluminum, copper and carbon steel samples were tested in the accumulation media zinc nitrate hexahydrate and calcium chloride hexahydrate for nine weeks at $55^{\circ} \mathrm{C}$. Samples of aluminum EN AW 1050A and copper EN CW004A subjected to corrosion test were in form of tubes, those of steel class 11 were in form of sheets. All the tested metals were submerged in the accumulation medium placed in a water bath tempered to $55^{\circ} \mathrm{C}$. Heating and cooling cycle of the accumulation media was simulated as the water bath thermostat was switched off during the weekends. The corrosion process was monitored once per week by weighing the samples on scales with the accuracy of $0.5 \mathrm{mg}$. The last steps included removal of corrosion products (ISO 8407:2009) and analysis of all samples by SEM and XRD.

\section{Results and Discussion}

In the $\mathrm{Zn}\left(\mathrm{NO}_{3}\right)_{2} \cdot 6 \mathrm{H}_{2} \mathrm{O}$ medium, samples of aluminum were the least degraded. A passive layer of $\mathrm{Al}_{2} \mathrm{O}_{3}$, which resisted corrosion was formed on their surface (Figs. 1 and 2).

Copper had a slightly higher corrosion rate than aluminum. Cross section of the sample showed that corrosion intruded to the depth of about $20 \mu \mathrm{m}$

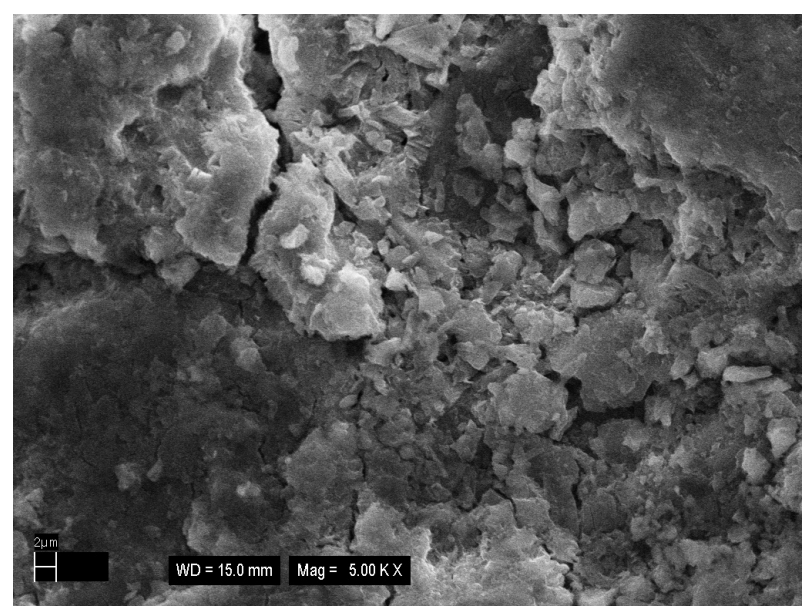

Fig. 1. Surface of aluminum after corrosion test in $\mathrm{Zn}\left(\mathrm{NO}_{3}\right)_{2} \cdot 6 \mathrm{H}_{2} \mathrm{O}$. and the corrosion layer at some sites reached up to $100 \mu \mathrm{m}$ (Fig. 3).

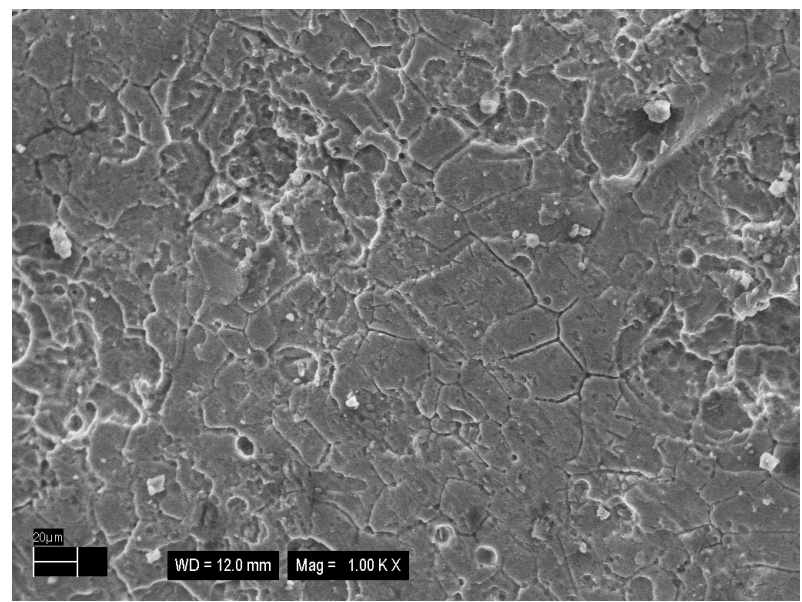

Fig. 2. Surface of aluminum after corrosion test in $\mathrm{Zn}\left(\mathrm{NO}_{3}\right)_{2} \cdot 6 \mathrm{H}_{2} \mathrm{O}$ (after removing the main corrosion products).

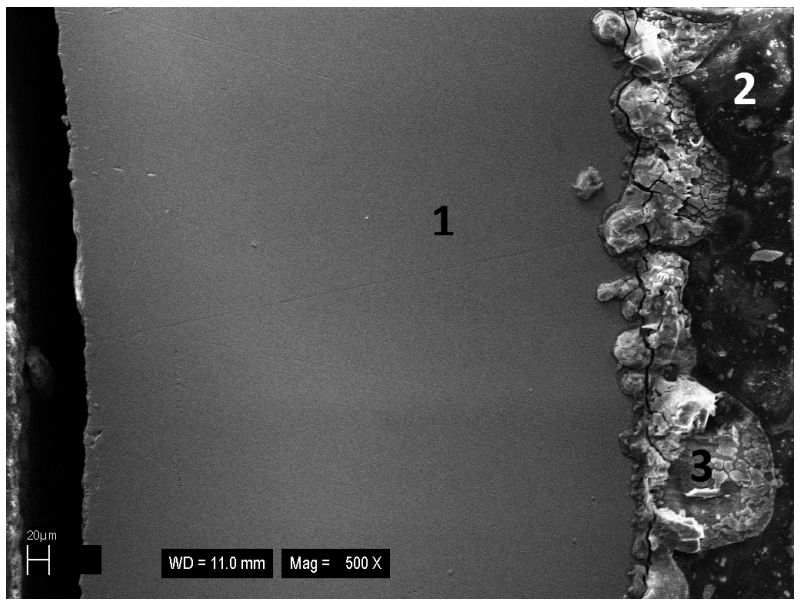

Fig. 3. Cross section of copper after corrosion test in $\mathrm{Zn}\left(\mathrm{NO}_{3}\right)_{2} \cdot 6 \mathrm{H}_{2} \mathrm{O} .1$ - metal; 2 - resin; $3-$ corrosion products.

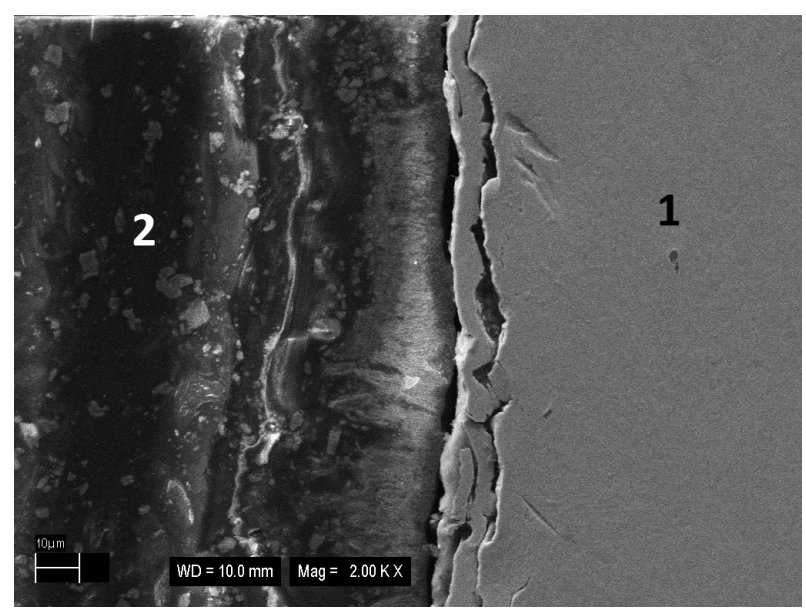

Fig. 4. Cross section of steel after corrosion test in $\mathrm{Zn}\left(\mathrm{NO}_{3}\right)_{2} \cdot 6 \mathrm{H}_{2}$ O. 1 - metal; 2 - resin. 
A layer of rust formed on the surface of steel and it was gradually peeled into the solution, where it subsequently dissolved. Thus, the highest weight loss was recorded and also the highest rate of corrosion was observed on steel samples (Fig. 4).

Results obtained in the calcium chloride medium were diametrically different from those obtained in zinc nitrate hexahydrate. Weight loss of aluminum samples was very low as a thin passivation layer was created on the surface. On the SEM record after the corrosion products removal, considerable damage from pitting corrosion (Fig. 5) intruding into depth of the material can be observed (Fig. 6), which was also confirmed by the cross section of the sample. Even if the corrosion rate is too low, the pitting corrosion is crucial as it shows that aluminum is not compatible with the studied PGM.

Samples of copper showed low weight loss values, thus also the corrosion rate was quite low. A layer of copper oxides was formed on the surface of the

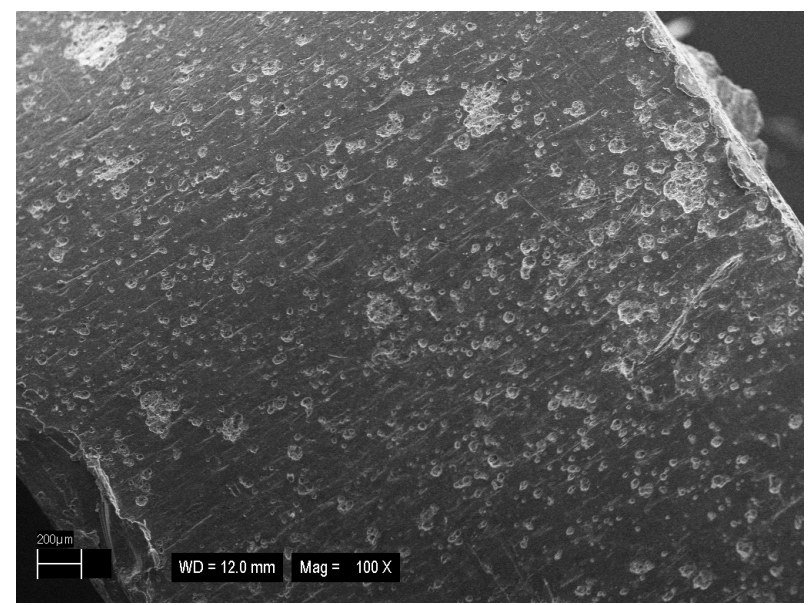

Fig. 5. Surface of aluminum after corrosion test in $\mathrm{CaCl}_{2} \cdot 6 \mathrm{H}_{2} \mathrm{O}$ (without corrosion products).

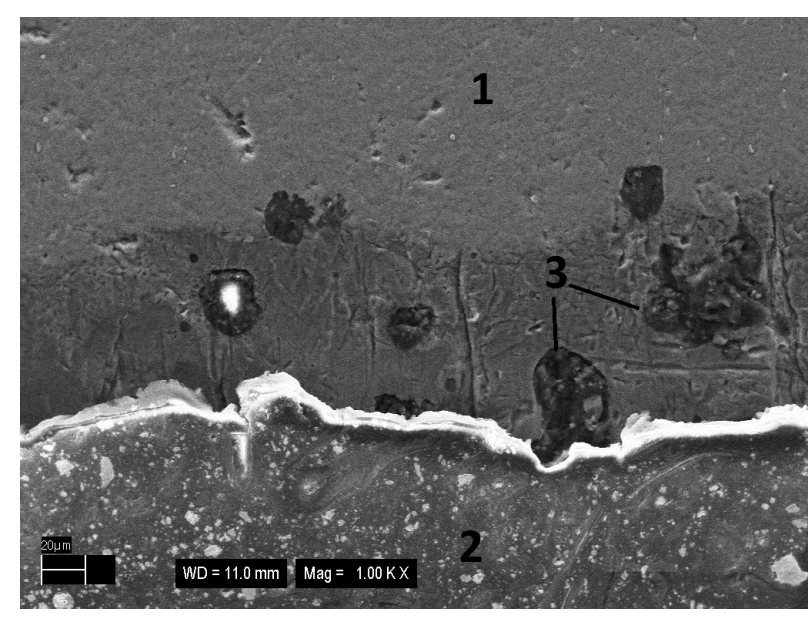

Fig. 6. Cross section of aluminum after corrosion test in $\mathrm{CaCl}_{2} \cdot 6 \mathrm{H}_{2} \mathrm{O}$ (without corrosion products).

1 - metal; 2 - resin; 3 - pitting corrosion.

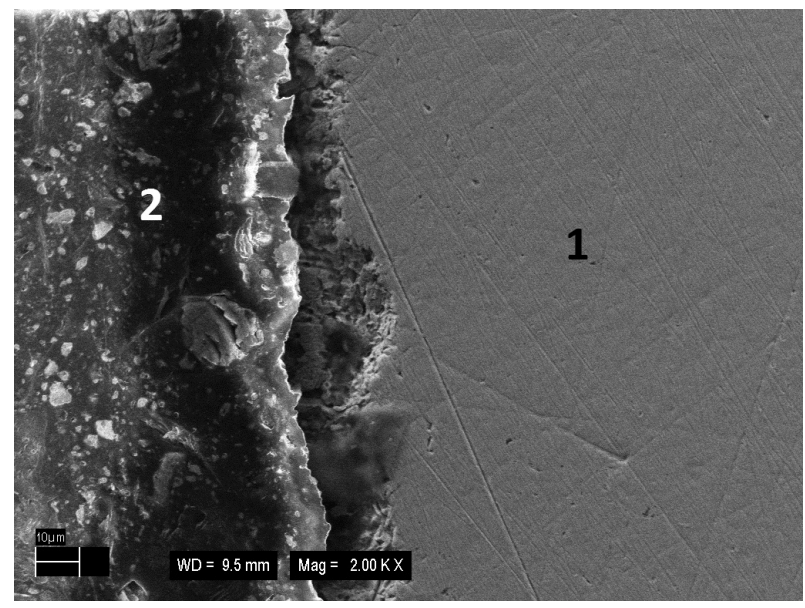

Fig. 7. Cross section of copper after corrosion test in $\mathrm{CaCl}_{2} \cdot 6 \mathrm{H}_{2} \mathrm{O} .1$ - metal; 2 - resin.

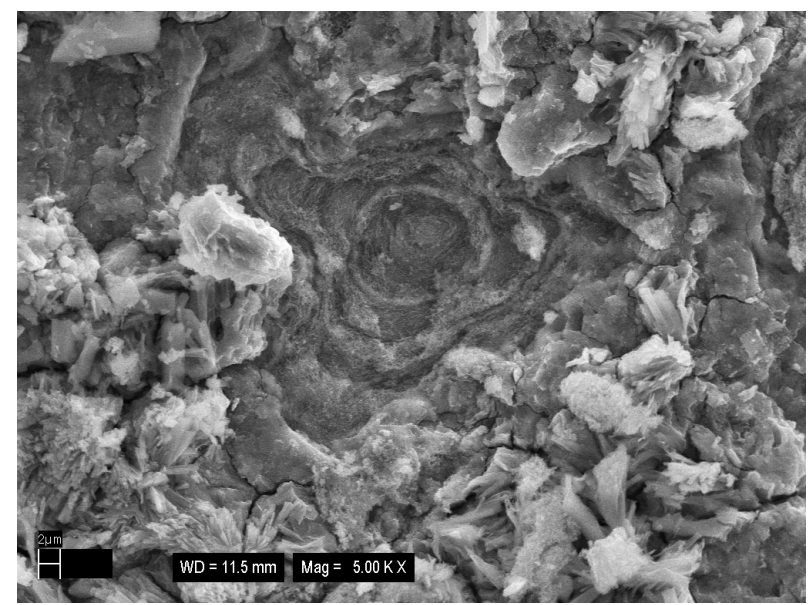

Fig. 8. Surface of steel after corrosion test in $\mathrm{CaCl}_{2} \cdot 6 \mathrm{H}_{2} \mathrm{O}$.

sample (Fig. 7), and slightly cracked surface was visible after its removal from the solution. Damage on the copper surface was less visible than that on aluminum. Although copper has higher corrosion rate, the type of corrosion attack is less aggressive than that for aluminum.

A layer of rust was created on the surface of steel (Fig. 8). According to all SEM records, significantly damaged surface was observed (Fig. 9). Steel showed the highest corrosion rate of all the metals tested in this medium.

Considering the literature sources (Cabeza et al., 2003; Davis, 2000; Moreno et al., 2014), it is possible to determine the recommended time of use of individual metals according to the corresponding corrosion rate (Tab. 1).

\section{Conclusion}

In both series of corrosion tests, steel had the highest corrosion rate, indicating that it was the 
Tab. 1. Corrosion rate of metals and recommendations for their use.

\begin{tabular}{llcl}
\hline Medium & Metal & $\begin{array}{c}\text { Corrosion rate } \\
{\left[\mathrm{mg} / \mathrm{cm}^{2} \cdot \text { year }\right]}\end{array}$ & Recommendation \\
\hline \multirow{2}{*}{$\mathrm{Zn}\left(\mathrm{NO}_{3}\right)_{2} \cdot 6 \mathrm{H}_{2} \mathrm{O}$} & $\begin{array}{l}\text { Aluminum EN } \\
\text { AW1050A }\end{array}$ & 61.78 & Not recommended for use longer than 1 year. \\
& Copper EN CW004A & 121.14 & Not recommended for use longer than 1 month. \\
& Carbon steel & 214.32 & Not recommended for use longer than 1 month. \\
\hline & Aluminum EN & 2.89 & $\begin{array}{l}\text { Recommended for long term use. However, it is not } \\
\text { recommended due to the pitting corrosion. }\end{array}$ \\
& AW1050A & 4.24 & $\begin{array}{l}\text { Recommended for long term use. } \\
\mathrm{CaCl}_{2} \cdot 6 \mathrm{H}_{2} \mathrm{O}\end{array}$ \\
& Copper EN CW004A & 9.45 & Recommended for long term use. \\
& Carbon steel & &
\end{tabular}

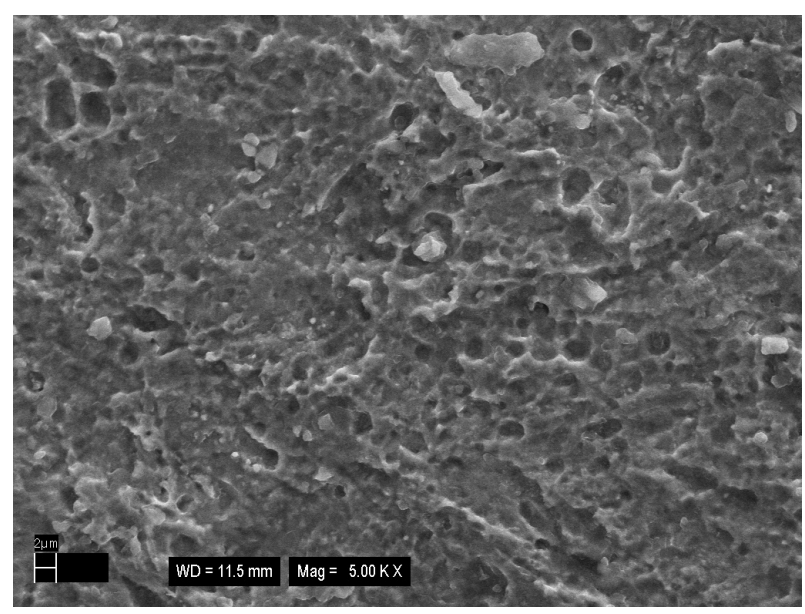

Fig. 9. Surface of steel after corrosion test in $\mathrm{CaCl}_{2} \cdot 6 \mathrm{H}_{2} \mathrm{O}$ (after removing the main corrosion products).

least resistant from the tested metals. Corrosion rate of aluminum was always the lowest because of the formation of a passivation layer of $\mathrm{Al}_{2} \mathrm{O}_{3}$. Based on the experiments in $\mathrm{Zn}\left(\mathrm{NO}_{3}\right)_{2} \cdot 6 \mathrm{H}_{2} \mathrm{O}$ media, aluminum is recommended for the use for a maximum of one year. Unlike aluminum, copper should be used for a maximum of one month. Steel, similar to copper, is not recommended for long term use. The results show that zinc nitrate hexahydrate is a very aggressive medium to the tested metals which is in agreement with the results published by (Cabeza et al., 2001a; Cabeza et al., 2001b). On that basis, zinc nitrate hexahydrate is not suitable to be used as an accumulation medium. Results of the experiments in $\mathrm{CaCl}_{2} \cdot 6 \mathrm{H}_{2} \mathrm{O}$ are totally different. According to the corrosion rates, all tested metals are recommended for long term use in this medium. However, although aluminum has the lowest corrosion rate, pitting corrosion has occurred in the calcium chloride medium, making it unsuitable for use. Copper does not have the lowest corrosion rate but due to the character of the corrosion, it is more suitable for use than aluminum. Thus, the most suitable combination for heat storages considering the tested metals and PCMs is copper and calcium chloride.

\section{Acknowledgement}

This publication is the result of the project implementation: Centre for materials, layers and systems for applications and chemical processes under extreme conditions - Stage II, ITMS No.: 26240120021 supported by the Research E Development Operational Programme funded by the ERDF. This work was supported by the Slovak Research and Development Agency under the contract NO. APVV14-0217 (Exploitation of gypsum into valuable chemical products and intermediates - EGYVACHEP) and funding by VUCHT a.s.

\section{References}

Cabeza LF, Illa J, Roca J, Badia F, Mehling H, Hiebler S, Ziegler F (2001a) Mater. Corros. 52: 140.

Cabeza LF, Illa J, Roca J, Badia F, Mehling H, Hiebler S, Ziegler F (2001b) Mater. Corros. 52: 748.

Cabeza LF, Svensson G, Hiebler S, Mehling H (2003) Applied Thermal Engineering 23: 1697.

Davis JR (2000) Corrosion - Understanding the Basics, 1 st ed. ASM, International.

Farid M et al. (2004) A review on phase change energy storage: materials and applications. In Energy Conversion and Management 45: 1597-1615.

Gil A, Medrano M, Martorell I, Lázaro A, Dolado P, Zalba B (2010) State of the art on high temperature thermal energy storage for power generation. Part $1-$ concepts, materials and modellization, Renew. Sustain. Energy Rev. 14: 31-55.

Moreno P, Miró L, Solé A, Barrenche C, Solé C, Martorell I, Cabeza LF (2014) Corrosion of metal alloy containers in contact with phase change materials (PCM) for potential heating and cooling applications, Applied Energy 125: 238-245.

Sharma SD, Sagara K (2005) Latent Heat Storage Materials and Systems: A Review, International Journal of Green Energy, 2: 1-56. 